\title{
A atividade curricular e pedagógica dos professores como fonte de tensões e dilemas profissionais: contributo para uma interpelação sobre a profissão docente
}

ARIANA COSME Universidade do Porto, Porto, Portugal

RUI EDUARDO TRINDADE Universidade do Porto, Porto, Portugal

RESUMO

As tensões e dilemas dos professores são o objeto de reflexão que está na origem da análise de dezesseis projetos de investigação, produzidos em Portugal, pelos quais se pretendeu fazer relação com a atividade curricular e pedagógica que aqueles protagonizam. Com base no trabalho realizado, concluiu-se que essa atividade nem sempre é objeto de interpelação explícita ou entendida como um fator relevante nos estudos que circunscrevem a atividade docente à discussão sobre o perfil dos professores e a resiliência profissional. Noutro sentido, aquela atividade assume outra importância nos estudos que propõem uma abordagem sistémica da profissão, ainda que neste âmbito a tensão entre a dimensão relacional e a dimensão curricular e pedagógica, entendida como uma tensão estruturante da reflexão sobre a natureza e as finalidades do trabalho docente, seja objeto de leituras que se produzam com base em diferentes pressupostos e com implicações distintas quanto ao modo de conceber esse trabalho.

PALAVRAS-CHAVE

gestão curricular e pedagógica; mal-estar docente; dilemas profissionais dos professores. 


\title{
THE CURRICULAR AND PEDAGOGICAL ACTIVITY \\ OF TEACHERS AS SOURCE OF TENSIONS AND \\ PROFESSIONAL DILEMMAS: CONTRIBUTION TO AN INTERPELLATION OF TEACHING PROFESSION
}

\begin{abstract}
Teacher professional dilemmas and tensions are de main topic of the sixteen research projects analysis, produced in Portugal, through which is intended to relate such dilemmas and tensions with teachers curricular and pedagogical activities. From the analysis that had been done is concluded that such activity is not object of explicit interpellation to the projects that circumscribed the discussion about teaching profession to teachers profiles or professional resilience. In a different perspective, that activity takes a further importance in the studies that propose a systemic approach of teacher's profession, even if the tension between relational dimension and curricular and pedagogical dimension, understood as a structural tension on the reflection about teachers work and their goals, can be read from different assumptions and has different implications about how the authors of that projects conceive teachers work.

\section{KEYWORDS}

curricular and pedagogical management; teaching malaise; teachers professional dilemmas.

\section{LA ACTIVIDAD CURRICULAR Y PEDAGÓGICA DE LOS DOCENTES COMO UNA FUENTE DE TENSIONES Y DILEMAS PROFESIONALES: CONTRIBUCIÓN PARA REFLEXIONAR SOBRE LA FUNCIÓN DOCENTE}

\section{RESUMEN}

Las tensiones y dilemas profesionales de los profesores son el objeto de reflexión en el origen de la análisis de dieciséis proyectos de investigación, producidos en Portugal, mediante los cuales se intenta relacionar aquellas tensiones y dilemas con la actividad curricular y pedagógica docente. A partir del trabajo realizado se concluye que la dicha actividad no es objeto de una interpelación explícita en los estudios que circunscriben la actividad docente a la discusión del perfil de los profesores y de su resiliencia profesional. En otra perspectiva, se da importancia a dicha actividad en los estudios proponen un enfoque sistémico de la profesión docente, aunque la existencia de una tensión entre la dimensión relacional y la dimensión curricular y pedagógica, comprendida como una tensión estructurante de la reflexión sobre la naturaleza y fines del trabajo docente, puede ser vista a partir de diferentes lecturas, interpretaciones e implicaciones acerca de la forma de pensar la actividad profesional de los docentes.

PALABRAS CLAVE

gestión curricular y pedagógica; malestar docente; dilemas profesionales de los docentes. 


\section{INTRODUÇÃO}

Este é um artigo no qual se pretende refletir sobre a natureza do trabalho docente num tempo em que as ambições educativas da escola se ampliaram, em que o alargamento da escolaridade obrigatória confronta essa instituição com novos desafios e exigências e, por isso, os professores têm que lidar tanto com um conjunto de ocorrências profissionais inéditas como com um conjunto de discursos, de origem diversa, que tende a produzir diferentes interpretações quer sobre a configuração, a amplitude e o significado desse trabalho, quer sobre seu impacto e importância.

A profissão docente tornou-se, então, uma profissão de risco no momento em que os professores hoje, ao ensinar, têm que "agir com urgência, decidir na incerteza" (Perrenoud, 2001, p. 15); têm que se defrontar com a perda de "um público garantido e submisso, disponível para aprender o que lhe era exigido (ou para interiorizar, humildemente, que não era capaz de aprender)"(Cortesão, 2000, p. 19); têm que encontrar, por isso, soluções curriculares e pedagógicas que possibilitem a diversificação das vias de acesso ao património de informações, instrumentos, procedimentos e atitudes culturalmente validado e socialmente valorizado; têm, finalmente, de aprender a lidar com as solicitações, tantas vezes contraditórias, dos responsáveis políticos, do mundo empresarial, do mundo académico e das comunidades na qual se inserem as escolas onde trabalham.

Diante de uma vida profissional por si só tão complexa, as vicissitudes, tensões e dilemas vividos pelos professores deixam de poder ser vistos como manifestações de incompetência para adquirirem, então, uma importância inquestionável como analisadores (Lourau, 1975) do trabalho docente nas escolas contemporâneas, os quais passam a ser entendidos como uma ferramenta analítica capaz de fazer emergir um conjunto de dimensões que, de outro modo, permaneceria oculto e que, assim, passa a estar disponível para ser sujeito à interpelação e reflexão públicas.

Foram tais vicissitudes, tensões e dilemas vividos pelos professores que constituíram o objeto do estudo a que este texto confere visibilidade. Um estudo que se construiu com base nos dados e nas reflexões produzidas por investigadores portugueses no âmbito de dezasseis projetos de investigação relacionados, ou não, com teses de doutoramento e, excecionalmente, com duas dissertações de mestrado. ${ }^{1}$ Pretendia-se compreender, de forma mais específica, se nesses trabalhos se estabelecia uma relação entre aquelas vicissitudes, tensões e dilemas e a atividade curricular e pedagógica dos professores, de modo que se pudesse identificar, em primeiro lugar, e interpelar, posteriormente, algumas leituras e interpretações que se têm vindo a produzir sobre a natureza do trabalho docente e as opções que, nesse âmbito, os professores poderão assumir.

1 Num caso, trata-se de trabalho que é relevante sobre os dilemas profissionais dos professores, produzido por uma investigadora, também ela relevante, no campo em questão (Caetano, 1997). No outro caso, estamos perante um estudo que exprime uma leitura que é incontornável no âmbito da reflexão sobre os ciclos de vida profissional dos professores (Loureiro, 1997), a leitura de Huberman (1989). 
Com essa decisão não se pretende negar a importância e a necessidade de se promoverem reflexões sobre outras dimensões relacionadas com o processo de reconstrução identitária dos professores, mas apenas identificar o campo de interesses em que nos situamos, quando decidimos analisar como se aborda, em estudos e reflexões academicamente credíveis, produzidos por autores portugueses reconhecidos como especialistas no domínio em questão, o estatuto e a importância que se atribui à atividade dos professores - enquanto decisores curriculares e pedagógicos - como dimensão da reflexão mais ampla sobre a identidade profissional docente.

\section{METODOLOGIA}

O conjunto de propósitos acabado de enunciar explica a seleção dos trabalhos que serviram de suporte a este estudo, os quais poderão ser enquadrados em virtude de três grandes categorias:

(i) a categoria relacionada com a reflexão de trabalhos que se debruçam sobre o sofrimento e o bem-estar dos professores, na qual foram incluídas as obras produzidas por Correia e Matos (2001), Seco (2002) e Mota-Cardoso e colaboradores (2002);

(ii) a categoria na qual as preocupações éticas e os dilemas profissionais dos professores são a problemática fundamental dos trabalhos selecionados, as quais, neste texto, circunscrevem-se aos trabalhos de Caetano (1997) e de Estrela (2010);

(iii) a categoria das obras que se debruçam sobre momentos e vicissitudes relacionados com os ciclos de vida profissional de professores, como é o caso, em primeiro lugar, dos trabalhos de Flores (2000), Alves (2001) e Jesus (2011), os quais dizem respeito ao processo de entrada na profissão docente. Em segundo lugar, selecionamos os trabalhos de Loureiro (1997), Lopes (2001) e Madureira (2012), que abordam as transições identitárias vividas pelos professores e as tensões de natureza pessoal e socioprofissional que tais transições pressupõem e, em terceiro lugar, os trabalhos de Gonçalves (2012) ou de Rodrigues (2012), que se referem ao impacto das políticas educativas sobre a configuração da profissão docente.

Para além dessas obras, foram lidas e analisadas outras três obras, os trabalhos de Teixeira (1995), de Cardoso (2002) e de Silva (2011), os quais, neste texto, são mobilizados de forma circunscrita para aprofundar assuntos ou confrontar ideias.

De um modo geral, há quatro considerações que aqui, perante a lista de obras selecionada, há obrigação de se fazer. A primeira consideração tem a ver com a opção por ter-se utilizado apenas trabalhos de investigação como objeto de reflexão, de modo que beneficiasse quer os cuidados metodológicos com que estes foram construídos, quer, ainda, a importância que tais trabalhos assumem na delimitação dos campos de saber e dos debates que têm lugar tanto no mundo contemporâneo como, igualmente, nos espaços relacionados com a produção do conhecimento académico. 
A segunda consideração diz respeito ao facto de não se ter abordado todas as obras disponíveis, tendo-se tentado construir um estudo credível não tanto em virtude do número de trabalhos analisados, mas da opção pela análise de trabalhos académicos produzidos por autores de referência, ou que foram orientados por autores de referência, publicamente reconhecidos como especialistas nas matérias abordadas.

A terceira consideração refere-se à opção por se tentar, sempre que possível, no âmbito de cada uma das categorias enunciadas, selecionar obras mais recentes, produzidas entre 2010 e 2013, e obras publicadas entre o fim dos anos de 1990 e os primeiros anos do século XX. Uma decisão metodológica que permitisse confrontar estudos realizados em dois períodos de tempo distintos, dado que essa é uma variável fundamental a ser considerada, tendo em conta o modo como as vicissitudes, as tensões e os dilemas profissionais vividos pelos professores poderão ser afetados pelas transformações do mundo, das políticas educativas e dos cotidianos em que vivemos.

A quarta consideração prende-se com a necessidade de referir que as obras em causa foram abordadas apenas em virtude do seu contributo para estudar as vicissitudes, tensões e dilemas dos professores, sabendo-se, no entanto, que esse não é o objeto de estudo preferencial de algumas delas. Fora da seleção proposta estão estudos e projetos de investigação relacionados diretamente com a problemática da gestão curricular e pedagógica ${ }^{2}$ porque, sendo esta uma variável fundamental a considerar no âmbito do estudo promovido, importa reconhecer que não é essa problemática que constitui o objetivo deste estudo. É verdade que seria possível estudar aquelas vicissitudes, tensões e dilemas como uma problemática subordinada às preocupações curriculares e pedagógicas dos professores, ainda que, nesse caso, se estivesse perante um estudo diferente daquele realizado. Num tal estudo, a problemática curricular e pedagógica impor-se-ia como uma problemática previamente selecionada para ser o objeto de discussão, enquanto no estudo que efetivamente se produziu se pretende compreender como essa problemática emerge ou não nas obras e nos trabalhos analisados e, se emerge, em que circunstâncias e de que maneira.

O plano metodológico seguido deve ser compreendido à luz dos conjuntos de intenções e de decisões acabados de enunciar. Foi em virtude desse plano que se realizou um trabalho cujo ponto de partida foi a leitura das obras mencionadas, de maneira que identificasse a reflexão explícita ou implícita produzida sobre as vicissitudes, tensões e dilemas profissionais dos professores. A etapa seguinte consistiu em promover o confronto entre as obras situadas dentro da mesma categoria analítica, objetivando identificarem-se e interpretarem-se as divergências, as tensões e as invariâncias das reflexões produzidas em cada uma dessas obras perante tais vicissitudes, tensões e dilemas. Foi a partir dos dados obtidos nessa segunda etapa

2 Os estudos relacionados com os projetos de formação inicial ou continuada de professores também não foram objeto de análise tendo em conta a especificidade e a complexidade da temática da formação que por si só merece um estudo próprio. 
que se acabou confrontando algumas problemáticas estruturantes que constituem o objeto de reflexão nas conclusões deste texto.

\section{ANÁLISE E DISCUSSÃO DOS RESULTADOS}

As leituras das obras sobre a problemática que orienta este estudo colocaram a necessidade de se encontrar uma estratégia de apresentação e discussão dos dados capaz de responder aos objetivos deste trabalho e à diversidade das reflexões produzidas. Daí que se tenha optado por apresentar os resultados do trabalho em virtude das categorias que presidiram à seleção das obras analisadas, as quais organizam a reflexão empreendida por meio deste texto.

\section{OS ESTUDOS SOBRE O SOFRIMENTO E A SATISFAÇÃO PROFISSIONAL DOS PROFESSORES: CONTRIBUTO PARA UMA INTERPELAÇÃO}

As obras selecionadas para abordar o sofrimento ou a satisfação profissional dos professores foram a de Correia e Matos (2001), a de Seco (2002) e Mota-Cardoso e colaboradores (2002). Não são obras equivalentes quanto aos pressupostos concetuais que as sustentam e às leituras que propõem sobre a reflexão que desenvolvem valendo-se do sofrimento e da satisfação profissional dos professores.

$\mathrm{Na}$ obra que Correia e Matos (2001) produziram, o sofrimento profissional dos professores terá que ser compreendido à luz de alguns acontecimentos que hoje marcam os cotidianos das escolas, nomeadamente a "precarização dos referentes que asseguravam uma relativa estabilização da profissão" (idem, p. 93). ${ }^{3}$ Se uma tal precarização é fonte de sofrimento, Correia e Matos acabam por identificar outras fontes, nomeadamente aquelas que têm a ver com "a relação coisificada com os alunos" (idem, p. 108). ${ }^{4}$ Estamos, assim, perante uma escola cuja representação "é povoada por alunos incompetentes", alunos "com deficiências gravíssimas, mesmo com falta de organização mental para a construção de textos", alunos que os professores ignoram mesmo quando jogam à bola nos corredores, "pois não vale a pena dizer nada, senão ainda nos atiram a bola à cabeça” (idem, p. 110).

É em uma Escola assim que o sofrimento profissional dos professores se explica pela descrença quanto às possibilidades de estimular o desejo de aprender dos seus alunos. Trata-se de uma sensação de impotência profissional que se en-

3 Uma das afirmações que poderá ilustrar essa proposição é aquela pela qual um dos professores inquiridos no estudo de Correia e Matos (2001, p. 93) afirma que "Quanto mais consciência tenho do trabalho que tenho feito, mais dúvidas tenho e menos contente estou com aquilo que faço".

4 Trata-se de uma conclusão que se constrói por meio da coleta de frases na qual se afirma que os alunos estão "muito pouco motivados, têm poucos conhecimentos, o ensino para eles não lhe diz nada... a escola não lhes diz praticamente nada, não estão habituados a pesquisar, não estão habituados a desenvolver trabalhos" (Correia; Matos, 2001, p. 108), ou que "têm uma competência linguística muito baixa e eu sinto que, para os corrigir, tenho que pôr de lado a aquisição de competências básicas que o programa considera fundamentais" (idem, p. 109). 
contra intimamente relacionada com a dimensão curricular e pedagógica da ação dos professores e à qual se acrescenta outra fonte de sofrimento que tem a ver com a falta de reconhecimento dos desafios e dificuldades de uma profissão hoje sujeita a um processo "de banalização simbólica do saber pedagógico como símbolo de distinção profissional do professor", o qual explica que "toda a gente ache que pode ser professor" (idem, p. 97). Uma constatação que não poderá deixar de ser relacionada com outra questão que Correia e Matos (idem) abordam quando refletem sobre os manuais escolares como instrumentos de ação e regulação pedagógica do trabalho docente.

Segundo os referidos autores, "até ao início da década de 80 parecia ser inquestionável o papel do manual como auxiliar de aprendizagem e como garante do prolongamento da influência do professor sobre o aluno para a esfera doméstica" (idem, p. 131), função esta que se alterou substancialmente quando os manuais escolares se começaram a afirmar "como reguladores do trabalho dos professores, como guias de ensino, como referências incontornáveis de uma ação pedagógica cada vez mais descentrada do professor enquanto agente de difusão de uma cultura e de transmissão de saberes científicos" (idem, ibidem). Ainda que não estejamos perante uma reflexão decorrente dos discursos produzidos sobre esse assunto pelos professores inquiridos, importa reconhecer que para Correia e Matos (idem) os manuais escolares passam a assumir um papel cada vez mais decisivo como dispositivos de instrumentalização da intervenção profissional dos professores e de desqualificação do trabalho docente, sobretudo quando os manuais contribuem para a cristalização de respostas curriculares e pedagógicas que se mostram inconsequentes como fautores de influência educativa.

São essas fontes de sofrimento profissional relacionadas com a desqualificação curricular e pedagógica dos professores que acabam por explicar, na reflexão proposta por Correia e Matos (idem), outras ocorrências de mal-estar adjacentes e às quais os autores se referem quando explicitam o impacto da "escola dos silêncios" (idem, p. 114) na vida profissional dos docentes, evidenciando o peso da estratégia defensiva no nível das relações que os professores estabelecem entre si, de forma que preservem de qualquer tipo de discussão pública as vicissitudes privadas do exercício da profissão.

A obra de Seco (2002), que é resultado de sua tese de doutoramento em ciências da educação, aborda os fatores que poderão contribuir para explicar o bem-estar profissional dos professores. Enquadra-se numa orientação teórica distinta daquela que Correia e Matos (2001) assumem e que se encontra vinculada ao campo da psicologia, o que explica que Seco defina a relevância do seu estudo pelo facto de este poder contribuir para estruturar "estratégias que incidam sobre a construção e desenvolvimento de competências ao nível da personalidade do professor, competências perspetivadas como significativas para um melhor ajustamento às exigências da actividade docente e propiciadoras de satisfação profissional"(Seco, 2002, p. 160).

Considerando que os dados do seu estudo "parecem apontar para a possibilidade de a satisfação-insatisfação dos professores se situar num continuum único, regulado, simultaneamente, pelos efeitos tanto dos factores intrínsecos como extrínsecos ao trabalho" (idem, ibidem), Seco refere-se aos primeiros como aqueles 
que têm a ver com a realização de tarefas, as relações gratificantes com os alunos ou a "tomada de decisões ligadas ao trabalho docente (incluindo o desenvolvimento curricular)" (idem, ibidem). São, para a investigadora, fatores extrínsecos os que têm a ver com "os incentivos que encorajem os professores a pensar de forma inovadora [...] e a comprometerem-se em novos objectivos e padrões de desempenho" (idem, p. 161) que estimulem a "sua implicação e autonomia na construção, desenvolvimento e gestão da escola e do processo educativo" (idem, ibidem). Afirmando que "a experiência subjectiva de bem-estar docente implica não se colocar entre parênteses a pessoa que habita a profissão" (idem, p. 162), Seco conclui que é pela formação inicial e contínua de professores que se pode contribuir para o "desenvolvimento de uma personalidade profissional" (idem, ibidem).

Como se constata, ambas as obras estabelecem um vínculo entre o sofrimento ou o bem-estar profissional dos professores e as dimensões curricular e pedagógica subjacentes ao exercício da profissão, ainda que seja o trabalho produzido como resposta para enfrentar esse sofrimento com a necessidade de se promoverem mudanças que impliquem transformações quer quanto ao modo como se define o estatuto e o papel das escolas nas sociedades contemporâneas, quer quanto ao modo como essa redefinição, ao afetar o mandato e as expectativas que recaem sobre as escolas, terá de afetar o trabalho dos professores e as relações que aí têm lugar. A abordagem de Seco (2002), ainda que proponha de forma mais ou menos tímida e difusa a redefinição dos desafios e das exigências curriculares e pedagógicas com que os professores confrontam os seus alunos, defende sobretudo a possibilidade de se implementar um conjunto de medidas que, do exterior do grupo profissional de docentes, possa contribuir para a promoção do seu bem-estar psicológico.

Estabelecendo um confronto entre os dois trabalhos, é possível constatar que se está perante dois modos distintos de, por meio da reflexão sobre o sofrimento profissional dos professores, se promoverem leituras diferentes acerca das vicissitudes, das tensões e dos dilemas com os quais os docentes hoje se confrontam. A perspetiva de Seco enquadra-se numa tradição de estudos que subordinam a problemática do bem-estar docente à sua dimensão psicológica. Trata-se de uma tradição que teve o mérito de conferir visibilidade às novas "condições sócio-históricas em que se exerce a docência” (Esteve, 1992, p. 29), ainda que não deixe de exprimir uma abordagem circunscrita do sofrimento profissional dos professores, tal como se comprova pelo papel nuclear que Seco atribui à formação como instrumento de promoção do bem-estar desses profissionais. Trata-se de uma proposta que se aproxima da reflexão de um outro investigador, situado no mesmo campo, Jesus (2002), o qual constitui um dos autores de referência do estudo que Seco desenvolveu.

Não será por acaso que também esse investigador propõe um programa de prevenção do mal-estar docente no qual defende que os professores deverão adquirir "competências profissionais relevantes para aumentar a sua autoconfiança" (Jesus, 2002, p. 29), tornando-se "mais eficazes no confronto com potenciais factores de 'stress' e ajudando-os a transformar as situações de 'distress' em 'eustress' (idem, ibidem). Trata-se de um objetivo que, para Jesus, deverá ser inserido no quadro 
mais amplo do desenvolvimento de um projeto de formação "orientado para o desenvolvimento de qualidades pessoais e interpessoais que possam contribuir para uma prática de ensino personalizado e para a realização profissional do professor" (idem, ibidem).

Por fim, o estudo coordenado por Mota-Cardoso (2002) "permite, pela primeira vez, identificar para Portugal as causas" do "stress" dos professores portugueses. Trata-se de um estudo que é coordenado por um médico que trabalha na área da saúde ocupacional, o qual, segundo Cosme (2006, p. 61), defende:

uma perspetiva circunscrita e parcial do "stress" dos professores, no momento em que tende a subvalorizar, como dimensão incontornável da abordagem desta problemática, a dimensão pedagógico-cultural que configura o papel do professor como mediador do contacto/confronto que os seus alunos vão estabelecendo com o património cultural hoje disponível.

Nesse sentido, dos três trabalhos selecionados no âmbito dessa categoria, é aquele que tende a ignorar a dimensão curricular e pedagógica como uma componente necessária para se refletir sobre a natureza do trabalho docente.

Em comparação com a reflexão de Seco (2002) e a de Mota-Cardoso (2002), é possível concluir que o trabalho de Correia e Matos (2001) propõe uma leitura em que a atividade curricular e pedagógica assume outra centralidade na reflexão que os dois investigadores produzem. Sobretudo, não se pode negar que a obra de Seco recuse a importância de tal atividade, ainda que se possa afirmar que esta não é objeto de reflexão explícita. É uma leitura que se distingue da de Correia e Matos, para quem aquela atividade se afirma como um objeto de interpelação à medida que, justamente, se interpelam quer as vicissitudes, as tensões e os dilemas profissionais dos professores, quer, concomitantemente, as representações que se têm vindo a construir sobre o papel e a função da escola.

Em suma, enquanto para Correia e Matos (idem) a reflexão sobre as vicissitudes, as tensões e os dilemas profissionais vividos pelos docentes não pode ser dissociada da reflexão sobre as dimensões organizacional e política da escola, no caso de Seco (2002) e de Mota-Cardoso, as reflexões sobre a mesma problemática tendem a circunscrever o mal-estar docente às caraterísticas psicológicas dos professores e o seu bem-estar a projetos de formação capazes de permitir o desenvolvimento, por parte dos professores, de uma atitude de resiliência psicológica perante as situações profissionais adversas.

\section{OS ESTUDOS SOBRE AS PREOCUPAÇÕES ÉTICAS E OS DILEMAS PROFISSIONAIS DOS PROFESSORES: PERSPETIVAS E QUESTIONAMENTOS}

$\mathrm{Na}$ categoria dos estudos sobre as preocupações éticas e os dilemas profissionais dos professores, a questão que se colocava era a de saber se em tais estudos aquelas preocupações e dilemas se articulavam com os desafios e as exigências curriculares e pedagógicas com que os professores se confrontam cotidianamente e, caso isso se verificasse, como essa articulação era construída. Foram duas as obras a que se recorreu para realizar esse empreendimento, o trabalho de Caetano (1997) 
e o trabalho de Estrela (2010), no qual, num capítulo sobre a "dimensão pedagógica dos sentimentos dos professores" (idem, p. 46), inclui-se um estudo que remete para uma reflexão sobre a relação entre ética e sentimentos no qual a autora propõe uma reflexão sobre a "dimensão ética do profissionalismo docente" (idem, p. 67).

A primeira constatação é de que ambos os trabalhos analisados constituem um testemunho inequívoco de que a reflexão sobre a ética, como componente da ação educativa dos professores e sobre os dilemas que estes enfrentam no decurso do exercício da sua profissão, nos permite refletir sobre a importância das opções e das decisões curriculares e pedagógicas como fatores que emergem de tal reflexão.

Nesse sentido, importa começar por analisar o trabalho de Caetano (1997), que se afirma como um trabalho sobre os dilemas dos professores, os quais estuda agrupando-os em torno de quatro categorias:

(i) os dilemas da relação;

(ii) os dilemas relacionados com a organização curricular;

(iii) os dilemas da avaliação e

(iv) os dilemas do contexto institucional.

Como é expectável, são os dilemas relacionados com as decisões curriculares e com as decisões avaliativas que explicitamente corroboram a hipótese de que a vida dos professores, do ponto de vista das exigências, desafios, dificuldades e sucessos, não pode ser dissociada da atividade curricular e pedagógica que esses professores desenvolvem. Tais dilemas são aqueles em que os professores têm que decidir se devem ser mais ou menos diretivos; se devem obedecer às normas legais ou adaptar-se às circunstâncias e às suas convicções; se devem transmitir conhecimentos ou promover a formação pessoal e social dos seus alunos; se devem promover o trabalho para recuperar os alunos academicamente mais vulneráveis ou atender às circunstâncias e motivação dos alunos mais avançados e, em último lugar, se devem transmitir ou estimular a descoberta de valores (idem).

Os dilemas referentes à avaliação não podiam deixar de expressar, igualmente, a centralidade das decisões curriculares e pedagógicas como temáticas estruturantes da profissionalidade docente, elegendo Caetano um primeiro dilema que tem a ver com o ato de reprovar ou não reprovar quem não atinge objetivos mínimos ou com o ato de baixar ou não baixar o nível de exigência académica. $O$ segundo dilema diz respeito ao facto de se determinar, no domínio das decisões que têm a ver com a aprovação/reprovação dos alunos, se se deve valorizar o esforço dos alunos ou se se devem valorizar, antes, as suas capacidades. O terceiro dilema tem a ver, por sua vez, com a necessidade de os professores respeitarem o sistema de avaliação vigente ou usarem critérios e instrumentos próprios, enquanto o quarto dilema se resume à opção de atuar de acordo com a tradição institucional ou respeitar as suas conviçcões e a formação adquirida. O quinto, e último dilema, exprime-se pela opção entre avaliar, ou não, segundo a mesma bitola, os alunos que não tiveram uma preparação anterior adequada e aqueles que tiveram uma formação anterior competente e capaz (idem). 
É com base nesse quadro traçado por Caetano que se compreende melhor a natureza dos dilemas da relação (idem), os quais se estruturam em torno de uma dicotomia crucial: a da liberdade versus controlo. Trata-se de dilemas que merecem, no entanto, uma discussão mais aprofundada, dado que é pertinente perguntar se os poderemos dissociar de forma tão clara dos restantes dilemas atrás enunciados. Aqui tal assunto será falado tendo como referência o estudo de Estrela sobre os dilemas de caráter ético vividos por professores no âmbito do exercício da sua profissão. Assim, Estrela (2010) refere-se a distintos conjuntos de situações dilemáticas que têm a ver com "relação afectiva", "disciplina", "desenvolvimento curricular" (idem, p. 90), "escola” (idem, p. 92), "Ministério da Educação" (idem, p. 93), "relação com a profissão" (idem, p. 94), "relação com a sua família" e "relação consigo próprio" (idem, p. 95).

Se associarmos essa leitura acerca dos dilemas profissionais dos professores com o inventário, incluído em outro estudo sobre o investimento dos professores, referente às "experiências emocionalmente mais marcantes vividas ao longo da sua experiência profissional" (idem, p. 51), constata-se que a categorização apresentada acerca das situações dilemáticas é uma categorização pela qual se correm alguns riscos concetuais, os quais estão bem presentes na afirmação da autora quando esta considera que "mais que o sucesso ou insucesso das aprendizagens, são os aspectos relacionais que tornaram marcantes" os episódios que os inquiridos apresentam com "maior carga emocional pela positiva” (idem, ibidem). Lendo o já referido inventário, constata-se que este diz respeito a "manifestações de reconhecimento pelos alunos" ou "o agradecimento, alguns anos mais tarde, de uns alunos que a professora tinha reprovado e tinham compreendido o porquê" (idem, ibidem). Na referência às "situações marcantes pela negativa" (idem, p. 52), afirma-se, mais uma vez, que é "no aspecto relacional que surge o maior número de incidentes", destacando-se, então, "um conflito prolongado com os pais", "casos de indisciplina" e "o insucesso dos alunos em matérias delimitadas ou no aproveitamento final” (idem, ibidem).

Confrontando as categorias de dilemas antes enunciadas com as situações posteriormente referidas, verifica-se que não é rigoroso dissociar situações adjetivadas como relacionais de situações que remetem para o sucesso/insucesso escolar, já que, de acordo com os exemplos mobilizados, as situações designadas como "relacionais" afirmam-se, na maior parte dos exemplos propostos, por ocorrências que têm a ver com o desempenho escolar dos alunos. Admite-se que há uma dimensão relacional inequívoca nas situações narradas, as quais, no entanto, não poderão ser dissociadas de decisões curriculares e das opções pedagógicas assumidas pelos docentes.

Daí que seja necessário compreender os riscos que se correm quando se estabelece uma categorização referente a situações dilemáticas como aquela que a autora propôs, sobretudo porque pode contribuir para a desvalorização das dimensões curriculares e pedagógicas como dimensões capazes de explicar e compreender as vicissitudes, as tensões e os dilemas vividos pelos professores no âmbito 
do exercício da sua profissão, ${ }^{5}$ seja por meio da relação com alunos seja por meio da relação com os colegas ou com outros atores educativos com quem tenha que conviver. É de acordo com essa reflexão que se pode compreender melhor porque se considera ser necessário analisar os dilemas do contexto institucional, aqueles que, segundo Caetano, dizem respeito aos conflitos e tensões que ultrapassam a "esfera das competências de gestão da sala de aula" (Caetano, 1997, p. 203), tendo em conta o modo como tais dilemas podem influenciar as reflexões e as decisões curriculares e pedagógicas que ocorrem no seio das escolas.

Em suma, enquanto a reflexão sobre as situações de sofrimento e de bem-estar dos professores nos colocava perante o confronto entre uma perspetiva sobre o trabalho docente vinculada a uma abordagem sistémica desse trabalho e uma perspetiva mais focalizada nas qualidades pessoais dos professores, na reflexão sobre os dilemas o confronto é de caráter diferente. Ocorre entre uma abordagem que enquadra esses dilemas numa problemática de caráter curricular e pedagógico e uma abordagem que entende os dilemas como uma questão relacional, as quais se diferenciam entre si no momento em que a primeira tende a englobar e a modular a dimensão relacional, enquanto a segunda tende a olhar para as relações como uma componente dissociada das decisões curriculares e pedagógicas que têm que ser tomadas para se estimular a atividade dos alunos.

\section{OS ESTUDOS SOBRE PROJETOS DE TRANSIÇÃO IDENTITÁRIA E O IMPACTO DAS POLÍTICAS EDUCATIVAS NA REDEFINIÇÃO DA PROFISSÃO DOCENTE}

Os estudos, nessa categoria das obras que se debruçam sobre as transições identitárias vividas pelos professores, são, como já referido, de três tipos: aqueles que dizem respeito aos trabalhos que abordam o processo de entrada na profissão, como é o caso das obras de Flores (2000), Alves (2001) e Jesus (2011), os trabalhos que estudam, de modo diverso, momentos significativos relacionados com os ciclos de vida profissional de professores, a exemplo do que fazem Loureiro (1997), Lopes (2001) ou Madureira (2012) e, finalmente, os trabalhos de Gonçalves (2012) ou de Rodrigues (2012) que, do conjunto dos estudos selecionados, se debruçam sobre o impacto das políticas educativas na vida dos professores e na redefinição da profissão docente.

A leitura da obra $O$ encontro com a realidade docente (Alves, 2001) permite-nos compreender como as decisões relacionadas com a gestão do currículo e a gestão pedagógica se constituem como fontes de dilemas dos professores neófitos. Uma constatação que é corroborada quer pela leitura dos diários de estágio, quer pelos diários dos professores inquiridos no seu $1^{\circ}$ ano de ensino, os quais permitiram que o autor do estudo respondesse à questão "Que tipos de dilemas e incidentes críticos encontram as alunas-professoras/professoras principiantes na sua actuação

5 Trata-se de uma opção capaz de gerar alguns equívocos na abordagem, por exemplo, das manifestações de indisciplina escolar se contribuir para dissociar tais manifestações das decisões curriculares e pedagógicas assumidas pelos professores. 
pedagógica?” (idem, p. 657), por meio da elaboração de quinze tipos de dilemas, assim agrupados:

- Quatro diretamente relacionados com um contexto de prática de ensino: dilema de autocompetência; dilema de uma supervisão obrigatória; dilema relacional-motivacional; dilema preocupacional;

- Cinco diretamente relacionados com um contexto do $1^{\circ}$ ano de ensino: dilema socioprofissional; dilema de planeamento didático; dilema de controlo metodológico didático; dilema de preferência sobre discentes; dilema profissional-familiar;

- Seis comuns ao contexto de práticas de ensino e ao contexto do $1^{\circ}$ ano de ensino: dilema de controlo da aprendizagem; dilema de desempenho profissional; dilema relacional; dilema relacional-curricular; dilema de empenhamento; dilema de gestão curricular (idem, p. 659-660).

Como se constata, os dilemas enunciados relacionam-se quer com as metodologias de intervenção adotadas, e com as respostas encontradas para enfrentar a questão "Como intervir?", quer com a natureza das relações interpessoais e grupais que se estabelecem entre professores e alunos. Apesar de se poder reconhecer que há interações na sala de aula que não são redutíveis à dimensão cultural da intervenção dos professores, não é possível, mesmo assim, olhar para ambas as vertentes atrás referidas como se exprimissem a existência de fenómenos estranhos um ao outro. Trata-se de um pressuposto que o próprio Alves defende quando afirma que nas dificuldades sentidas pelos professores neófitos se identificam aquelas que têm a ver com as dificuldades relacionais que são interpretadas pelo investigador como dificuldades "conexas com dificuldades do domínio curricular e motivacional [...], sem esquecer as sentidas na esfera do controlo da aprendizagem e do desempenho profissional" (idem, p. 650).

O trabalho de Flores (2000) é, do ponto de vista das preocupações que o animam, equivalente ao trabalho de Alves, debruçando-se igualmente sobre o período referente à entrada na profissão. É nas conclusões do trabalho que a autora afirma:

[...] problemas dos professores principiantes situam-se, fundamentalmente, no campo didático e remetem, sobretudo, para a arena das decisões interativas de ensino. O elevado número de alunos por turma, a motivação dos alunos, a individualização e diferenciação do ensino, a atenção aos ritmos de aprendizagem dos alunos, a indisciplina, os procedimentos avaliativos e a gestão do tempo emergem como os fatores mais problemáticos, tornando-se no cavalo de batalha dos neófitos. (idem, p. 249)

Trata-se das dificuldades que remetem, mais uma vez, para o domínio da gestão curricular e pedagógica. Não é de estranhar, por isso, que as

[...] áreas prioritárias de apoio/formação apontadas pelos neófitos remetam, por um lado, para a integração no ambiente da escola e, por outro, para aspetos 
didáticos ligados ao comportamento dos alunos, às estratégias e motivação, a aspetos legislativos e à avaliação. (idem, p. 250)

O terceiro trabalho relacionado com o início da profissão docente é mais recente, da autoria de Jesus (2011), que confirma a centralidade que as tensões e os dilemas de natureza curricular e pedagógica assumem no período referente à entrada na profissão quer pelas exigências e desafios que têm a ver diretamente com o trabalho que realizaram como docentes, ${ }^{6}$ quer pelos "sentimentos de incapacidade, de dúvida, de culpa e de insegurança" (idem, p. 364), resultantes de um projeto de formação inicial que deveria "compreender matérias mais próximas e necessárias aos quotidianos das escolas" (idem, ibidem).

Dos trabalhos que estudam os momentos significativos relacionados com os ciclos da vida profissional de professores, começa-se por apresentar os principais contributos do estudo de Loureiro (1997), no qual se faz sentir a influência da abordagem de Huberman (1989) acerca dos ciclos da vida profissional dos professores. Tendo abordado as carreiras de um conjunto de professores de Viseu, o estudo de Loureiro permite concluir que a gestão do processo de ensino e de aprendizagem é um fator invariante de caráter transversal que afeta o processo de desenvolvimento profissional dos docentes, ainda que, tal como acontece na leitura que Estrela (2010) propõe acerca dos dilemas profissionais dos professores, nos confrontemos com a tensão que se estabelece entre a dimensão relacional da profissão e a dimensão referente à gestão curricular e pedagógica. É nas conclusões do estudo que se pode ler que a componente socioafetiva deve ser valorizada como um fator decisivo no modo como os docentes explicam as suas vivências profissionais. Daí que, segundo Loureiro (1997), os "aspectos cognitivos permaneçam secundarizados nas representações destes professores" (idem, p. 155), o que "não é de modo algum surpreendente dada a natureza relacional da actividade docente"(idem, ibidem). Admitindo-se que é legítimo concluir o que Loureiro conclui, importa, no entanto, discutir as vulnerabilidades e os riscos do tipo de representações que o seu estudo revela.

O segundo trabalho selecionado é da autoria de Lopes (2001). Trata-se de um trabalho subordinado ao objetivo de "produzir conhecimento a propósito da construção de identidades profissionais de docentes do $1^{\circ}$ Ciclo do Ensino Básico" (idem, p. 467), valendo-se de um projeto de investigação-ação pelo qual se propõe um novo tipo de preocupações e de enquadramento educacional que Lopes carateriza como "mais centrado na participação construtora das crianças no processo de aprendizagem, no trabalho pedagógico entre professores e interturmas e na problematização do impacto da escola como um todo na qualidade da educação fornecida" (idem, idem). Um projeto que contava com a participação de onze professoras, subdivididas por dois grupos: um constituído por professoras mais velhas e experientes e o outro grupo, o grupo em estudo, no qual se encontrava professoras

6 As dificuldades na gestão do tempo, os problemas com a planificação, avaliação e diferenciação, a frustração sentida pela "ausência de participação directa dos alunos na organização e gestão da sala de aula” (Jesus, 2011, p. 365) são alguns dos problemas relacionados com a dimensão "gestão curricular e pedagógica". 
mais novas que se caraterizavam pelo seu compromisso com projetos e movimentos de inovação pedagógica ou pela frequência de cursos de nível superior.

É pela análise dos resultados que se pode estabelecer o confronto com o trabalho anterior, o de Loureiro (1997), quanto à problemática da dissociação entre a dimensão relacional e a dimensão referente à gestão curricular e pedagógica, no momento em que Lopes conclui que o processo de redefinição identitária vivido pelas docentes esteve na origem de uma mudança que afetou a sua abordagem sobre "a componente organizacional", a "componente pedagógica" e "a componente comunicacional” (Lopes, 2001, p. 440). No entanto, e ao contrário do trabalho anterior, tais componentes não são entendidas como componentes insulares, na medida em que, para se compreender a leitura que se produz relativamente a uma componente, é necessário articulá-lo com as leituras que se produzem sobre as restantes componentes.

É essa abordagem de caráter sistémico que constitui um dos contributos mais relevantes do estudo de Lopes, já que o processo de redefinição identitária dos docentes é explicado pelo facto de, na "componente pedagógica", "a relação com as crianças" passar a "ser problematizada também no quadro de referência mais geral que é a escola” (idem, ibidem). Daí que as professoras se refiram menos ao trabalho que têm que realizar com as crianças "e mais ao modo como a escola globalmente responde às necessidades” destas (idem, ibidem). Trata-se de uma mudança que potencia, mas também decorre de outros modos de abordar a organização escolar e os processos de comunicação que aí têm lugar. Não foi por acaso, então, que no nível da "componente organizacional" a atenção das professoras passou a fazer-se sentir sobre "a ultrapassagem de obstáculos relativos à arquitectura do edifício" ou sobre a "problematização [do papel] das empregadas da escola como auxiliares", discutindo-se também "uma maior e melhor coordenação do trabalho em geral, uma melhor organização de certas actividades do foro colectivo (recreios e festas) e uma melhor rede de distribuição da informação" (idem, ibidem). Os dados relativos à "componente comunicacional" mostram, finalmente, que, entre outras coisas, diminuíram as "referências ao trabalho profissional entre colegas como aspecto problemático na escola" e passou-se a falar mais da necessidade de estabelecer "trocas de experiências" entre docentes (idem, p. 441).

Trata-se de uma perspetiva que, por exemplo, conflitua com a reflexão de Teixeira (1995) sobre a leitura que essa autora produziu sobre a profissão docente valendo-se da relação entre professores e escolas. No estudo por si produzido, a dimensão organizacional e o clima educativo dessas escolas são vistos como a causa cujo efeito tem a ver com o modo como afetam a vida profissional dos professores, os quais são vistos como seres "em relação numa profissão de relação" (idem, p. 160). Ou seja, pelo estudo produzido por Teixeira defrontamo-nos, em primeiro lugar, com uma abordagem linear da relação entre organização escolar e profissão docente. Em segundo lugar, defrontamo-nos tanto com o problema da valorização exclusiva da dimensão relacional da profissão como com o problema da aceitação dessa dimensão como algo adquirido que, por isso, não é necessário caraterizar e definir.

O outro trabalho, da autoria de Madureira (2012), é também mais recente. Trata-se de um estudo que visa compreender as motivações e os processos de 
transição profissional vividos por professores que em dado momento da carreira decidiram passar para os quadros da educação especial, no qual seriam responsáveis por programas de intervenção educativa dirigidos para crianças com necessidades educativas específicas. No momento em que o estudo foi produzido, os professores entrevistados defrontavam-se com uma mudança jurídica que conduzia à redefinição do seu trabalho nas equipas de educação especial, o que constitui uma ocorrência decisiva para se compreender o processo de transição identitária estudado e as conclusões que a investigadora propõe.

É tendo em conta tal ocorrência que se pode compreender as razões porque Madureira identifica três tipos de identidades nesse grupo de docentes: "a identidade pedagógica resiliente, a identidade plural vulnerável e a identidade ambígua vulnerável" (idem, p. 288). Assim, para a investigadora, é no primeiro tipo de identidade por si mencionado que a "reconfiguração por integração não conflitual das identidades profissionais (passada e atual)" se torna possível, o que "acontece independentemente da idade, do género, da formação de base e da fase da carreira em que [os professores] se encontram quando optam pela educação especial" (idem, ibidem). Os docentes que são identificados em virtude da sua "identidade plural vulnerável" são caraterizados, por sua vez, como profissionais que evidenciam "frustração, cansaço profissional e o desejo de abandono da educação especial” (idem, ibidem). Finalmente, a "identidade ambígua vulnerável" permite retratar

[...] um professor à procura de si próprio enquanto profissional; um professor para quem a experiência na educação especial constituiu um espaço de crescimento e de desenvolvimento profissional num tempo determinado, mas onde não se revê atualmente, perante o perfil de desempenho previsto na lei. (idem, p. 290)

Um dos aspetos mais interessantes, do ponto de vista dos objetivos do estudo que se torna público por meio deste texto, tem a ver com a importância que o trabalho de Madureira atribui aos "conhecimentos pedagógicos" (idem, p. 287), os quais são entendidos como os "factores determinantes da socialização, da identificação com a profissão, em suma, da intenção de permanecer na educação especial" (idem, ibidem). Não se desvalorizam "as influências que antecedem o início da profissão; a experiência docente no ensino regular; as circunstâncias associadas à opção pela educação especial" (idem, ibidem) e até "as caraterísticas pessoais" (idem, p. 255) dos professores que participaram no estudo, mas, perante o novo quadro legislativo que impõe mudanças quanto ao trabalho docente que passarão a ter que realizar no âmbito da educação especial, é a dimensão curricular e pedagógica que sobressai para explicar o processo de transição identitária estudado.

Nesse sentido, trata-se de um estudo cuja pertinência, tal como o estudo de Lopes (2001), pode ser aferida pelo modo como contribui para responder não só ao problema concetual que a dissociação entre a dimensão relacional e a dimensão da relação curricular e pedagógica introduz na reflexão sobre as vicissitudes, as tensões e os desafios da profissão docente, mas também quando contribui para abordar a importância dessa dimensão como componente de uma abordagem sistémica da 
natureza do trabalho docente em que as relações de causa-efeito tendem a ser suplantadas por uma visão em que as diferentes variáveis envolvidas na reflexão sobre a natureza daquele trabalho se intercondicionam e afetam mutuamente.

Para Madureira (2012), a biografia, as razões que justificam a opção pela docência, o impacto da formação inicial, a qualidade da socialização no chamado ensino regular e, posteriormente, a socialização na chamada educação especial são fatores que não poderemos negligenciar como situações que explicam o modo como os professores assumem o exercício da profissão. Um exercício que, como o estudo de Madureira nos ajuda a comprovar, se afirma em virtude das opções, das decisões e das ações curriculares e pedagógicas dos professores, as quais se afirmam também pelos processos relacionais que envolvem afetos e emoções e que terão que ser compreendidas em virtude de ocorrências biográficas e de interações com outros, dentro e fora das escolas.

O trabalho de Gonçalves (2012) estuda o impacto de dois diplomas jurídicos, o do Estatuto da Carreira Docente e o da Avaliação do Desempenho Docente, na reconfiguração da(s) identidade(s), da carreira e do desenvolvimento profissional dos professores do $1^{\circ}$ ciclo do ensino básico. É um trabalho no qual se constata que os professores envolvidos no estudo sentem que aqueles diplomas contribuem para a desqualificação do seu trabalho, defendendo a autora que

[...] a emergência de um comportamento competitivo (por exemplo, esconder o saber dos colegas), acompanhado pela intensificação de tarefas e pelo excesso de trabalho burocrático que o professor passou a enfrentar diariamente, ocupam o professor de forma exagerada, sufocando-o em papéis e deixando-lhe pouco tempo para o cumprimento das tarefas essenciais no seu (des)empenho profissional: a preparação de aulas, a definição de estratégias de aprendizagem e a construção de materiais didáticos. (idem, p. 332)

Como se verifica, há duas conclusões relevantes no conjunto de argumentos apresentado: uma diz respeito ao facto de se corroborar a centralidade da dimensão curricular e pedagógica como dimensão estruturante da profissão docente e outra afirma que tem a ver com uma insinuação que posteriormente se confirma, a qual diz respeito ao fenómeno que Nóvoa (2005) designa por transbordamento das funções da escola e, subsequentemente, da atividade dos professores, que assim passam a assumir um conjunto mais diversificado de papéis e de responsabilidades por atividades que são vistos, no estudo de Gonçalves (2012), como um contributo para descaraterizar a profissão, a qual é "constantemente 'chamada' para resolver problemas socioeconómicos e culturais do país, tendendo cada vez mais a configurar a profissão como de um trabalhador social, mesmo sabendo-se que não corresponde ao cerne da profissão docente" (idem, p. 333).

No outro trabalho que se debruça igualmente sobre "o impacto que as políticas educativas dos últimos dez anos têm tido na (re)definição da profissão e do 
trabalho docente", ${ }^{7}$ o estudo desenvolvido por Rodrigues (2012) também se refere à problemática do transbordamento das funções docentes, ainda que a investigadora não conclua, perante os dados de que dispõe, que se está diante de um processo de desqualificação profissional dos professores. No entanto, chama atenção para a intensificação e a complexificação do trabalho docente por via das maiores ambições educativas que hoje as escolas assumem e dos desafios subsequentes com os quais, por isso, os professores são confrontados. São esses desafios que explicam, então, um novo conjunto de exigências que se consubstanciam, por um lado, nas problemáticas da colegialidade e da reflexividade docentes ou no impacto da utilização das novas tecnologias no cotidiano profissional dos professores e, por outro, nas exigências relacionadas com o processo de avaliação que nas escolas se começou a implementar. Nesse sentido, conclui que há um efetivo impacto das políticas educativas no trabalho docente que se fazem sentir no modo como os professores se defrontam com outros dilemas e novas tensões ou ainda perante algumas situações de mal-estar nas quais se destacam aquelas que se prendem com a perceção de uma autonomia profissional deficitária e com uma atividade mais sujeita ao erro e às imperfeições.

Pode afirmar-se, em jeito de conclusão, que o que esses dois últimos estudos nos mostram é que as transições identitárias ou a tentativa de estabelecer ciclos no nível da vida profissional dos professores não poderão ser dissociadas das decisões de política educativa que contribuem para modelar o tempo em que tais transições ocorrem e aqueles ciclos se afirmam, tal como Silva (2011) o defende quando reflete sobre o impacto do "processo de globalização educacional" nas "vivências profissionais e na identidade dos professores" (idem, p. 287).

\section{CONCLUSÕES}

Com este artigo pretendeu-se contribuir para a reflexão sobre o trabalho docente interpelando tal atividade com a análise das vicissitudes, tensões e dilemas profissionais dos professores, tentando compreender como um conjunto diverso de estudos credíveis, que por diferentes vias permitem abordar essa problemática, as relacionam com a atividade dos professores como decisores ou gestores curriculares e pedagógicos. Como referido, não se nega a importância de outras dimensões como componentes do processo de afirmação identitária dos professores, mas pretendia-se analisar e compreender que importância aqueles estudos atribuíam à dimensão "gestão curricular e pedagógica" na configuração de tal processo, dada a importância desta como dimensão que permite hoje identificar o trabalho dos professores.

A análise confirma que a dimensão curricular e pedagógica tende a ser ignorada no estudo coordenado por Mota-Cardoso (2002) e desvalorizada no estudo de Seco (2002), tendo em conta que estamos perante trabalhos preocupados com a resiliência psicológica dos professores. É verdade que em nenhum momento tais estudos negam a importância da dimensão da gestão curricular e pedagógica, ainda que o segundo desses estudos tanto a circunscreva a uma variável contextual, como

7 Resumo da tese de doutoramento da autoria de Rodrigues (2012). 
se fosse apenas um cenário em que os professores exercem a profissão, como não reflete explicitamente sobre tal dimensão.

Trata-se de uma opção que é credora do espaço epistemológico que a psicologia parece configurar, na medida em que não é só o trabalho de Mota-Cardoso (2002) e de Seco (2002), ou os de Esteve (1992) e Jesus (2002) que exprimem uma perspetiva sobre a vida profissional dos professores centrada quase que exclusivamente na valorização das variáveis psicológicas pelas quais pretendem caraterizar os docentes. O trabalho de Cardoso (2002) sobre a recetividade à mudança e à inovação pedagógica, por parte dos professores, comunga dos mesmos pressupostos quando aí se afirma que se pretende proceder "à identificação dos professores mais predispostos a inovar" (idem, p. 103), identificar as melhores condições para promover "o recrutamento e eventual selecção dos candidatos aos cursos vocacionados para o ensino" (idem, p. 105) ou "estimular a sua permanência no sistema educativo" (idem, p. 106). Por fim, a autora valoriza "a possibilidade de modificar algumas das características de personalidade do professor" (idem, p. 107).

Se esses são propósitos que dizem respeito às variáveis referentes à relação entre inovação pedagógica e personalidade do professor, importa identificar agora as implicações que dizem respeito à relação entre inovação pedagógica e contexto escolar. Nesse caso, o estudo valoriza a criação de condições quer "para uma interacção mais salutar entre professores e alunos" (idem, p. 110), quer "para o desenvolvimento profissional e pessoal do professor (idem, p. 111) ou para se proporem algumas mudanças que dizem respeito à "formação continuada” (idem, p. 115). Como se pode constatar, as referências às dimensões pedagógica e curricular são difusas ou implícitas, destacando-se as preocupações com o indivíduo-professor e as suas competências, sem se cuidar de interpelar as conceções dos professores sobre os seus compromissos sociais, sobre a escola, sobre os atos de ensinar e de aprender ou desprezando-se a relação dos professores com o conhecimento e o seu "tacto pedagógico" (Nóvoa, 2009, p. 30).

Se esse conjunto de estudos tende a menorizar como objeto de reflexão explícita a dimensão da gestão curricular e pedagógica como componente fundamental do trabalho dos professores e instrumento de interpelação das suas vicissitudes, das tensões e dos dilemas profissionais, importa reconhecer que esta não é a abordagem dos restantes estudos analisados cuja reflexão acerca de tal dimensão se faz sentir com base em pressupostos e perspetivas distintas, justificando que se discuta, neste texto, a tensão entre a dimensão relacional e a dimensão curricular e pedagógica e, posteriormente, o modo como uma abordagem sistémica sobre a profissão docente permite enfrentar tal tensão.

A tensão entre a dimensão relacional e a dimensão curricular e pedagógica é, de facto, uma das problemáticas que os estudos que analisados melhor evidenciam. Uma problemática que é ignorada no estudo coordenado por Mota-Cardoso (2002). Uma problemática que também nos coloca quer perante o défice de explicitação relativamente à dimensão relacional como componente que permite caraterizar a profissão docente e o trabalho dos professores (Teixeira, 1995), quer pela sua aceitação tácita (Loureiro, 1997; Seco, 2002), quer, finalmente, pela sua valorização 
heurística, relacionada com a comodidade metodológica da condução dos estudos (Estrela, 2010).

Seja como for, não está em causa reconhecer a importância da dimensão relacional como componente do processo de construção ou de redefinição da identidade dos professores, mas discutir se é plausível identificar, por exemplo, o sofrimento, as dúvidas, as alegrias, as hesitações ou as contradições dos professores independentemente dos desafios e exigências curriculares e pedagógicas que estes têm que viver e enfrentar. A única possibilidade de aceitar tal possibilidade é partir do princípio de que tais desafios e exigências ou são inevitáveis ou não são questionáveis, o que constitui, conforme se perspetiva, uma leitura pouco interessante porque parece entender como adquirido o facto de que para os professores não há alternativa perante o "paradigma pedagógico da instrução" (Trindade; Cosme, 2010, p. 28). Nesse caso, a dimensão relacional tende a ser encarada como uma manifestação do toque de humanidade dos professores em um ambiente educativo no qual estes se afirmam pelo trabalho prescritivo que promovem quer no nível da gestão curricular, quer no nível da animação pedagógica. Daí que o problema da opção que agora se discute tenha a ver com o facto de se interpretar as vicissitudes, as tensões e os dilemas como problemas relacionais e nunca como problemas curriculares e pedagógicos que até se podem exprimir publicamente como problemas relacionais.

Nesse sentido, importa referir, entre outros, a importância de trabalhos como os de Correia e Matos (2001), de Lopes (2001) e de Madureira (2012), pelo facto de proporem uma leitura sistémica da profissão docente, contribuindo desse modo para superar o equívoco das perspetivas que promovem abordagens atomizadas do trabalho dos professores e se encontram sujeitas a uma racionalidade científica que visa, acima de tudo, estabelecer relações de causa-efeito entre as diversas componentes que possam resultar desse produto de atomização.

Todos os estudos referidos comprovam que a atividade profissional dos professores deverá ser compreendida em virtude do seu enquadramento tanto em espaços profissionais singulares ${ }^{8}$ como em escolas que, apesar do que têm em comum, não são organizações idênticas, como, ainda e finalmente, em um determinado tempo histórico cuja influência sobre aquela atividade está bem patente nos trabalhos que abordam o impacto das políticas educativas sobre a profissionalidade docente (Gonçalves, 2012; Rodrigues, 2012; Silva, 2011). Por isso, aqueles estudos também nos permitem compreender que não é possível abordar o trabalho dos professores em virtude de uma perspetiva tecnocrática da profissão, como se tal exercício implicasse apenas o desenvolvimento estrito de competências nos domínios da gestão do currículo ou da gestão do trabalho pedagógico na sala de aula. Essas competências são decisivas para explicar o trabalho docente e a sua natureza, mas há outras variáveis que é necessário mobilizar para se produzirem abordagens capazes de dar conta da complexidade do que está em jogo (Day, 2004), até do ponto de vista dos investimentos, das opções e do processo de apropriação das ideias e dos

8 Estes espaços dizem respeito aos diferentes ciclos de escolaridade no qual o trabalho dos professores ocorre. 
dispositivo que influenciam os professores a gerirem o currículo e o trabalho nas salas de aula da forma como o fazem.

Finalmente, é com base naqueles estudos que poderemos discutir se uma reflexão sobre as vicissitudes, as tensões e os dilemas vividos pelos professores no âmbito de uma profissão que se define como "um processo de comunicação complexo” (Dubar, 1997, p. 108) poderá ser circunscrita “a uma 'etiquetagem' autoritária de identidades predefinidas na base de trajetórias individuais" (idem, ibidem). Trata-se de uma questão bastante relevante tendo em conta o esforço para ajudar a compreender que as carreiras dos professores não dependem apenas de decisões individuais (Huberman, 1989), porém não se pode iludir a respeito do peso que têm nessas carreiras as singularidades da vida profissional em virtude da qual os docentes podem perfilhar diferentes pontos de vista sobre os atos de ensinar e aprender ou manifestar níveis de perseverança distintos no nível da concretização, em termos curriculares e pedagógicos, dos seus propósitos profissionais. É que sendo admissível pensar que essas conceções e suas implicações praxeológicas afetam o modo como um docente se perceciona, então será necessário valorizá-las no âmbito da reflexão sobre as vicissitudes, tensões e dilemas profissionais que atravessam a vida dos professores e contribuir, por essa via, para interpelar a natureza do trabalho que os professores pensam e realizam.

\section{REFERÊNCIAS}

Alves, F. C. O encontro com a realidade docente: ser professor principiante. Lisboa: Instituto de Inovação Educacional, 2001.

Caetano, A. P. Dilemas dos professores. In: Estrela, M. T. (Org.). Viver e construir a profissão docente. Porto: Porto Editora, 1997. p. 191-221.

Cardoso, A. P. O. A receptividade à mudança e à inovação pedagógica: o professor e o contexto escolar. Porto: Edições ASA, 2002.

Correia,J. A.; Matos, M. Solidões e solidariedades nos quotidianos dos professores. Porto: Edições ASA, 2001.

Cortesão, L. Ser professor: um ofício em vias de extinção. Reflexões sobre práticas educativas face à diversidade no limiar do século XXI. Porto: Edições Afrontamento, 2000.

Cosme, A. Ser professor numa escola e num tempo de incertezas: desafios, exigências e dilemas profissionais. 2006. 407f. Tese (Doutoramento em Ciências da Educação) Faculdade de Psicologia e de Ciências da Educação da Universidade do Porto, Porto, 2006.

Day, C. A paixão pelo ensino. Porto: Porto Editora, 2004.

Dubar, C. A socialização: construção das identidades sociais e profissionais. Porto: Porto Editora, 1997.

Esteve, J. M. O mal-estar docente. Lisboa: Escher, 1992. 
Estrela, M. T. Profissão docente: dimensões afectivas e éticas. Porto: Areal Editores, 2010.

Flores, M. A. A indução no ensino: desafios e constrangimentos. Lisboa: Instituto de Inovação Educacional, 2000.

Gonçalves, R. H. B. Identidade(s), carreira e desenvolvimento profissional. Um estudo junto de professores do $1^{\circ}$ CEB. 2012. 382f. Tese (Doutoramento em Ciências da Educação, Especialidade de Desenvolvimento Curricular) - Universidade do Minho, Braga, 2012.

Huberman, M. La vie des enseignants: evolution et bilan d'une profession. Paris: Actualités Pédagogiques et Psychologiques, 1989.

Jesus, M. E. C. B. Tornar-se professor do $1^{\circ}$ ciclo do ensino básico: um estudo sobre o início da carreira docente. 2011. 421f. Tese (Doutoramento em Ciências da Educação, Especialidade de Observação e Análise da Relação Educativa) - Universidade do Algarve, Faro, 2011.

Jesus, S. N. Perspectivas para o bem-estar docente: uma lição de síntese. Porto: Edições ASA, 2002.

Lopes, A. Libertar o desejo, resgatar a inovação: a construção de identidades profissionais docentes. Lisboa: Instituto de Inovação Educacional, 2001.

Lourau, R. A análise institucional. Petrópolis: Editora Vozes, 1975.

Loureiro, M. I. O desenvolvimento da carreira dos professores. In: Estrela, M. T. (Org.). Viver e construir a profissão docente. Porto: Porto Editora, 1997. p. 117-159.

Madureira, I. L. P. Tornar-se professor de educação especial: uma abordagem biográfica. 2012.332f. Tese (Doutoramento em Educação, Formação de Professores) - Universidade de Lisboa, Lisboa, 2012.

Mota-Cardoso, R. et al. O stress nos professores portugueses: Estudo IPSSO 2000. Porto: Porto Editora, 2002.

NóvoA, A. Evidentemente. Porto: Edições ASA, 2005.

Professores: imagens do futuro presente. Lisboa: Educa, 2009.

Perrenoud, P. Ensinar: agir na urgência, decidir na incerteza. 2. ed. Porto Alegre: Artmed, 2001.

Rodrigues, E. M. P. As politicas educativas e o impacto no trabalho dos professores. 2012. 474f. Tese (Doutoramento em Ciências da Educação) - Universidade de Aveiro, Aveiro, 2012.

Seco, G. M. S. B. A satisfação dos professores: teorias, modelos e evidências. Porto: Edições ASA, 2002.

Silva, F. M. F. R. Saberes e construção de identidades profissionais docentes no ensino secundário em contexto de globalização: o caso dos/as professores/as de economia. 2011. 320f. Tese (Doutoramento em Educação) - Universidade Lusófona de Humanidades e Tecnologias, Lisboa, 2011.

Teixeira, M. O professor e a escola: perspectivas organizacionais. Lisboa: Editora McGraw-Hill de Portugal, 1995. 
Trindade, R.; Cosme, A. Escola, educação e aprendizagem: desafios e respostas pedagógicas. Rio de Janeiro: WAK Editora, 2010.

\section{SOBRE OS AUTORES}

Ariana Cosme é doutora em ciências da educação pela Universidade do Porto (Portugal). Professora da mesma instituição.

E-mail:ariana@fpce.up.pt

Rui Eduardo Trindade é doutor em ciências da educação pela Universidade do Porto (Portugal). Professor da mesma instituição.

E-mail: trindade@fpce.up.pt

Recebido em 16 de dezembro de 2014

Aprovado em 11 de fevereiro de 2016 